\title{
A Hybrid Approach Based on Fuzzy TOPSIS-AHP for Ranking and Classifying MOOC Key Acceptance Factors
}

\author{
Neeraj Chopra, J. C. Bose University of Science and Technology, YMCA, India \\ (iD) https://orcid.org/0000-0002-0969-3574 \\ Rajiv Sindwani, J. C. Bose University of Science and Technology, YMCA, India \\ (iD) https://orcid.org/0000-0001-7457-6457 \\ Manisha Goel, J. C. Bose University of Science and Technology, YMCA, India
}

\begin{abstract}
This investigation is done during COVID-19 to identify, rank, and classify MOOC (massive open online course) key acceptance factors (KAFs) from an Indian perspective. A systematic literature review identifies $11 \mathrm{KAFs}$ of MOOC. One more novel factor named 'contingent instructor' is proposed by the authors considering pandemic and new normal post-COVID-19. The paper implements two popular fuzzy MCDM (multiple-criteria decision-making) techniques, namely fuzzy TOPSIS and fuzzy AHP, on 12 KAFs. The fuzzy TOPSIS approach is used to rank factors. Affordability, performance expectancy and digital didactics are found as the top three KAFs. Fuzzy AHP classified KAFs into three groups, namely high, moderate, and low influential. Examination of the literature indicates that this study is among the first attempt to prioritize and classify MOOC KAFs using fuzzy TOPSIS and fuzzy AHP approach. The results offer managerial guidance to stakeholders for effective management of MOOC, resulting in higher acceptance rate. Likewise, this investigation will upgrade the comprehension of MOOC KAFs among academicians.
\end{abstract}

\section{KEYWORDS}

COVID-19, Fuzzy AHP, Fuzzy MCDM, Fuzzy TOPSIS, Key Acceptance Factors, MOOC

\section{INTRODUCTION TO THE STUDY}

The educational domain is changing quickly due to progressions in the Information and Communication Technologies (ICT) (Paliwoda-Pękosz \& Stal, 2015; Sharma et al., 2017). Massive Open Online Course (MOOC) is one of such provision responsible for changing educational domain. MOOC is an open online learning environment that caters the need of learners but significantly differing from earlier online education approaches (Alraimi et al., 2015). The features that distinguish MOOC from other online approaches are massiveness, openness, free, and quality education. (Liyanagunawardena et al., 2013; Ebben \& Murphy, 2014; Stracke et al., 2018). Despite benefits, MOOC providers are confronting with learner's high attrition rate. The MOOC completion rate is around 10\% (Gregori et al., 2018). Students' incessant exit from courses puts learning and education in danger and blocks the formative advancement of MOOCs. The legitimate explanations given by researchers for low completion rate were: (1) limited self-regulated learning aspects; (2) lack of basic computing skills; (3) clashes with 
other students during discussion; and (4) the sense of isolation (Hew \& Cheung, 2014; Shapiro et al., 2017). Nevertheless, Laurillard (2016) found mostly MOOC learners as professionally highly qualified instead of deprived ones as initially imagined. The primary reason is that mostly courses are offered in English language. These aforementioned reasons restrain MOOCs from achieving the objectives of inclusive education. Thus, a study is needed to identify factors that are critical for learners to accept MOOC. But majority of the literature showed that mostly MOOC studies were conducted from the learners' perspective of developed nations. Based on that true generalisation of the facts cannot be done. This motivated researchers to conduct study of MOOC acceptance in a densely populated developing nation like India for better generalisation of facts. It was also noticed that very few MOOC studies were conducted in Indian context (Nemer \& O'Neill, 2019). Hence, researchers examined the subject matter with three purposes. First, to identify key acceptance factors (KAFs) from the extant MOOC literature. With due consideration to earlier work, the current work reassesses the identified KAFs during pandemic for broad generalisation of results. Second, implementing multi-criteria decision-making (MCDM) techniques for ranking and classification of MOOC KAFs, which has not been widely discussed. Third, the outcome presents a comprehensive KAF list, critical for MOOC designers, developers and providers. They need to focus on these KAFs to fulfil the expectations of MOOC learners. As a result, the popularity of MOOC among learners will increase.

The remaining portion of the study is as follows. The following section systematically examines prior MOOC literature to identify KAFs. The subsequent section conceptual development of adopted methodology discusses algorithm of two MCDM techniques namely, fuzzy TOPSIS and fuzzy AHP along with their application on MOOC KAFS. The findings and discussion section presents the results. Contributions and conclusion section discusses the implications of the study along with concluding remarks. Finally, future bearings and shortcomings of this study are briefly discussed under the limitations and future direction section.

\section{Identification of MOOC KAFs}

To identify MOOC KAFs from the extant literature, Moher et al., (2009) guidelines of PRISMA (Preferred Reporting Items for Systematic Reviews and Meta-Analyses) were followed. Liberati et al. (2009) claimed that these guidelines make literature review process clear and transparent. Various studies used them. For example, the study conducted by Hughes-Morley et al. (2015) on factors affecting recruitment during depression. Based on them, a review protocol is made that includes search strategy, criteria for including and excluding an article, evaluation of quality, extraction of data, and data analysis.

a) Search Strategy: Automated search strategy was performed on three different repositories 'Scopus', 'Web of Science', and 'ERIC'. Search query string used were "MOOC acceptance" OR "MOOC adoption" OR "Massive open online course" AND "acceptance" OR "adoption". The studies published in English language during the period of January 1, 2010 to July 31, 2020 were taken for screening. The screening was done by examining their titles and abstracts. Studies fully satisfying the criteria mentioned in table 1 were shortlisted.

b) Quality assessment: Full text of shortlisted studies were examined for their quality appraisal based on specified criteria adapted from Nguyen-Duc et al., (2015) (refer to table 2). Every criterion had four possible scores: entirely fulfilled (3), sufficiently fulfilled (2), little fulfilled (1), and completely unfulfilled (0). Now, studies were arranged as per their quality score for analysing their rigorousness, credibility, and relevance. 
Table 1. Inclusion and exclusion criteria

\begin{tabular}{|c|c|}
\hline Criteria & Inclusion criteria \\
\hline I1 & Scholarly articles published in peer review journals \\
\hline I2 & $\begin{array}{r}\text { Scholarly articles described the application of technology acceptance theory or model for } \\
\text { adoption / acceptance of MOOC }\end{array}$ \\
\hline I3 & Recent version of study is included if many articles reported the same \\
\hline E1 & Exclusion criteria \\
\hline E2 & Scholarly literature not published in English language \\
\hline E3 & Grey literature such as conference proceedings, book chapter and editorials etc \\
\hline E4 & Duplicate articles \\
\hline
\end{tabular}

c) Data extraction: To pull out information like Paper ID, References, Publisher, Theories/ Model Studied, and factors taken etc., researchers recorded information in a well-defined format.

d) Data analysis: Studies were critically examined based on factors and theories or models employed.

Initial automated search retrieved 3313 studies from the abovementioned repositories. Their detailed lists were exported to excel for reference management and duplicate removal. After removing 966 duplicate studies, 2347 potential studies were left. After implementing inclusion and exclusion criteria on potential studies, 56 studies were selected for quality assessment. Quality assessment criteria resulted in 36 studies having average quality score greater than 1.5 (refer to figure 1). For reliability check of selected studies Kappa statistic (k) developed by Cohen (1960) was used. It was found to be $\mathrm{k}=0.906$. Landis and Koch (1977) claimed that Kappa statistic in the range of 0.81 to 1.00 informs strong reliability. Extensive review of 36 selected studies leads to identification of 11 key factors. Furthermore, authors proposed one new factor considering prevailing pandemic scenario as well as post Covid-19 situation. Figure 2 shows the pictorial representation of twelve key acceptance factors. Brief explanation of twelve KAFs is as follows:

1. Performance Expectancy (PE): The extent to which learner believes that studying MOOC would certainly support in obtaining professional and career benefits (Venkatesh et al., 2003). After studying 116 studies, Williams et al., (2015) noticed that in $80 \%$ of studies PE was observed as strong determinant of behavioural intentions to adopt (BIA). Similar observation was also noticed in some studies conducted in educational settings (Chellapalli \& Kumar, 2016; Mulik et al., 2018; Hooda \& Jain, 2018).

Table 2. Quality assessment criteria

\begin{tabular}{|c|c|}
\hline Code & Criteria \\
\hline C1 & Problem statement: The research objectives are properly explained and well-motivated \\
\hline C2 & $\begin{array}{c}\text { Research design: MOOC adoption or acceptance theories used are relevant for supporting the } \\
\text { systematic review process }\end{array}$ \\
\hline C3 & Data Collection: Factors used in the study are most relevant for achieving objectives \\
\hline C4 & Data analysis: Data analysis used in the study is properly explained \\
\hline C5 & Conclusions: Findings are clearly reported and supports result \\
\hline
\end{tabular}


2. Contingent Instructor: Due to the Covid-19 outbreak studies were suspended abnormally due to closure of educational institutes. At that time, many educational institutes opted for online education. But still, some institutes were not able to provide online education due to lack of resources. Here, MOOCs came as a boon for learners as well as educational institutes. March'2020 MOOC enrolment numbers verified the same (Shah, 2020). For instance, in March 2020, Coursera, The National Law University of Delhi, and some other MOOC providers gave free access of their MOOCs to schools and colleges affected by the coronavirus. It is clearly evident that sometimes situation demands acceptance of technology. Following the lines, a factor called Contingent Instructor is propelled by authors. The contingent instructor works as a substitute faculty in case non-availability of subject teacher and helps in completing the leftover syllabus. For instance, Abdeen et al. (2008) observed the extraordinary contribution of e-learning in beating the troublesome circumstances made by political issues and physical divider boundaries built by the Israeli possessing powers in the West Bank, Palestine.

3. Digital Didactics: It is technology enabled teaching method followed in MOOCs for active engagement of learners during the course for successfully achieving the learning outcomes expressed in the curriculum (Kansanen \& Meri,1999). MOOC didactic educational actions permits learners to select their personalised learning path for building their interest and motivate them to participate in learning activities. It also includes adjustment to new learning modalities both as learner and designer utilizing ICT, development of evaluation plans, and understanding for collaborative, useful, reflective, dynamic, and reliable learning.

4. Affordability: The extent to which the expense of learning MOOCs fits within the budget of learner. It measures the probability of students choosing a paid course, semi-paid course (Mohapatra et al., 2015) which shapes learner's perception (Rao, 2006). In April 2020, the UN's International Labour Organization (ILO) claimed that about 400 million workers doing jobs in India's informal sector are most likely to be pushed deeper into poverty due to Covid-19. In addition to this, most of the population belongs to the middle and lower-income groups. So, affordability matters to them. Mohapatra \& Mohanty (2016) noticed a positive association between affordability and behavioural intentions to utilize.

5. Self-Regulation: It refers to learners' capacity to schedule task, assignments and activities for timely completion of MOOC (Onah \& Sinclair, 2016). Zhou et al., (2017) noticed that the learner with high capacity of self-regulation performs better during the MOOC learning procedure because they generally are progressively certain, steady, and persevering. Self-regulation was found to apply the most grounded effect on students' aim to embrace MOOCs (Ma \& Lee, 2019).

6. Information Security: It refers to safety from malicious or accidental misuse of resources while studying in online mode (Adams \& Blandford, 2003). To achieve security of information there are three basic requirements: confidentiality, integrity, and availability (Serb et al., 2013). There should be no risk of loss of confidential information in order to maintain learners' trust in the web-based learning environment. It impacts learner's perceptions of a system's robustness, reliability, and trustworthiness (Adams \& Blandford, 2003). Hence, it is one of the mandatory factors of MOOC acceptance.

7. Facilitating Conditions: The extent to which learners believes that an organizational and specialized technical infrastructure is available and supports in completing MOOC (Zhenghao et al., 2015). Williams et al., (2015) empirically verified that it impacts behavioural intentions to utilize directly. Moreover, its empirical evidence can be seen educational settings also (Fianu et al., 2018).

8. Social Influence: The extent to which learner will undertake MOOC for skill enhancement to meet changing demands of social environment (Venkatesh et al., 2003). The opinion of others such as companions, partners, guardians and instructors would matter with regards to the choice of utilizing MOOC (Mulik et al., 2018). Williams et al., (2015) found significant relationship between social influence and behavioural intentions to use. 
9. Willingness to Earn a Certificate: It refers to the desire that encourages the individuals to join MOOCs with an objective of obtaining the certificates for purposes like career advancement and recognition. Various studies demonstrated that one of the core reasons behind registration in MOOCs for students is gathering as many as course completion certificates as possible (Macleod et al., 2015). The recognition of MOOC certifications by employers and administrative bodies is a strong determinant for learners to take up MOOC for professional benefits (Mohapatra \& Mohanty, 2016).

10. Perceived Reputation: Paulsen (1993) noticed that institutes' reputation impacts the student's choice to enrol in the institution. It is an abstract impression of the MOOC offering institution's quality, impact, student satisfaction, and trustworthiness (Alraimi et al., 2015). Mostly MOOC are developed by elite institutions giving necessary believability to the learners (Gefen et al., 2003). Mohapatra \& Mohanty (2016) found that perceived reputation has a strong influence on the aim to embrace MOOC.

11. Effort Expectancy: The extent to which learner believes that easiness level provided by MOOC platform contributes towards effective learning (Zhenghao et al., 2015). To put it simply, a userfriendly learning environment could be easily accepted by learners..

12. Interaction and Engagement: Alghamdi et al. (2011) characterized the MOOC learning activities as the connections and coordinated efforts among members and various kinds of learning items such as animated videos, quizzes to improve the learners' understanding of the MOOC content and accomplish the learning targets within the learning procedure. Learner engagement in MOOC here refers active participation of learner during the course evaluated by an instructor through overt behaviours. For example, participation in discussion forums, and queries raised by learners etc. (Gewnhi et al., 2013).

\section{Conceptual Development of Adopted Methodology}

The literature clearly highlighted the importance of fuzzy multi-criteria decision making (FMCDM) in solving problems which are intrinsically imprecise, fuzzy and carries uncertainty (Chang et al.,2014). It requires both subjective and objective information. To provide support to the subjective evaluation done by experts, FMCDM utilises computational and mathematical tools (Banaitiene et al., 2008). Though Quadri et al., (2020) noticed its application in educational domain, but its application for understanding key reasons behind MOOC acceptance is still unexplored. The current study proposes the application of two popular FMCDM techniques, (1) Fuzzy AHP and (2) Fuzzy TOPSIS for MOOC KAFs classification and ranking respectively. The techniques successfully handled issues like the selection of best alternative, evaluating and prioritising dimensions (Zhao \& Guo,2014).

\section{Fuzzy TOPSIS (FTOPSIS)}

FTOPSIS is intuitive, easy to compute, comprehend and contains a sound logic for rational representation of human choice. FTOPSIS was used in many studies. For instance, the study conducted by Sun and Lin (2009) to evaluate the competitive advantage of shopping sites. The study conducted by Agrawal et al. (2015) for prioritisation of critical success factors for reverse logistics implementation.

\section{FTOPSIS Algorithm}

The steps applied in the study are outlined as follows (Chen,2001; Zhao and Guo, 2014):

Step 1 A definite 5-point linguistic scale was selected for rating the importance of factors on linguistic terms as low (L), fairy low (FL), medium (M), fairly high (FH), and high (H) (Chen, 2001; Agrawal et al., 2015) (refer figure 3). Experts rate factors using it. Rating is further converted into the triangular fuzzy numbers (TFNs) using transformation rules specified in table 3 (Agrawal 
Figure 1. Procedure of systematic review

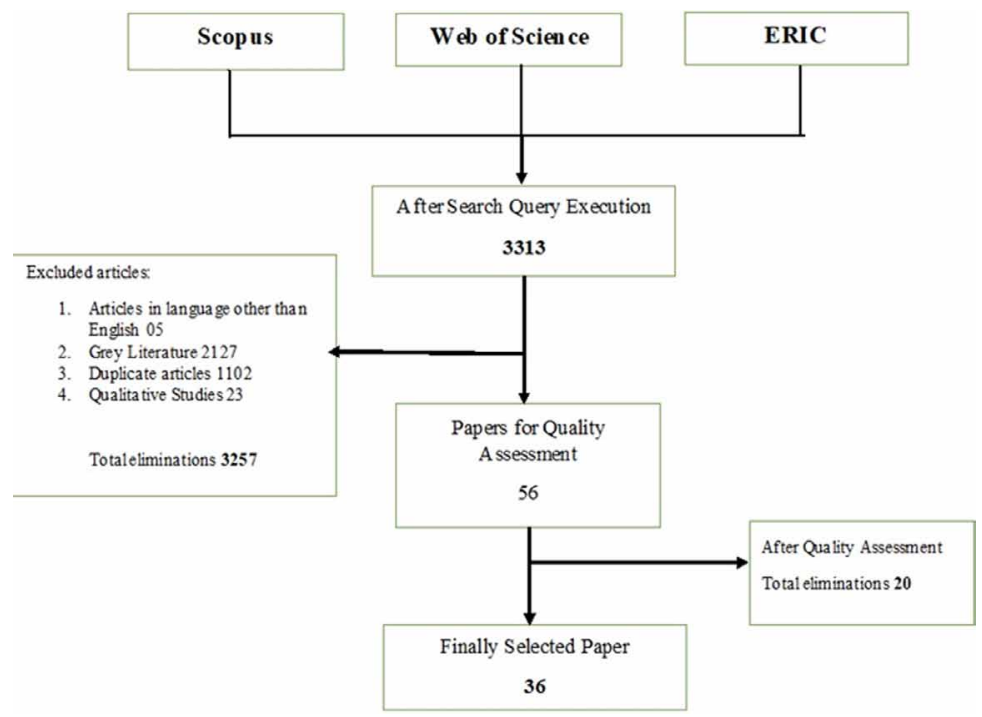

et al., 2015). TFNs (Laarhoven and Pedrycz, 1983) $\tilde{A}$ can be best understood as triplet $\left(a^{L}, a^{M}, a^{R}\right)$, having membership function $\mu_{\tilde{A}}$ and is expressed as:

$A= \begin{cases}0 & \text { for } x<a^{L} \\ \frac{x-a^{L}}{a^{M}-a^{L}} & \text { for } a^{L} \leq x<a^{M} \\ \frac{a^{R}-x}{a^{R}-a^{M}} & \text { for } a^{M} \leq x \leq a^{R} \\ 0 & \text { for } x>a^{R}\end{cases}$

where $a^{L}, a^{M}, a^{R}$ are crisp numbers and their values lies in the range $\left(-\infty<a^{L} \leq a^{M} \leq a^{R}<\infty\right)$. $a^{L}$ denotes the lower limit of data available for evaluation whereas $a^{R}$ denotes upper limit.

Step 2 Construction of the fuzzy decision matrix with TFNs in every cell.

$$
A=\left[\begin{array}{ccccc}
a_{11} & a_{12} & a_{13} & \ldots & a_{i n} \\
a_{21} & a_{22} & a_{23} & \ldots & a_{2 n} \\
a_{31} & a_{32} & a_{33} & \ldots & a_{3 n} \\
\ldots & \ldots & \ldots & \ldots & \ldots \\
a_{i 1} & a_{i 2} & a_{i 3} & \ldots & a_{i n} \\
a_{m 1} & a_{m 2} & a_{m 3} & \ldots & a_{m n}
\end{array}\right]
$$




\section{Figure 2. MOOC Key Acceptance Factors}

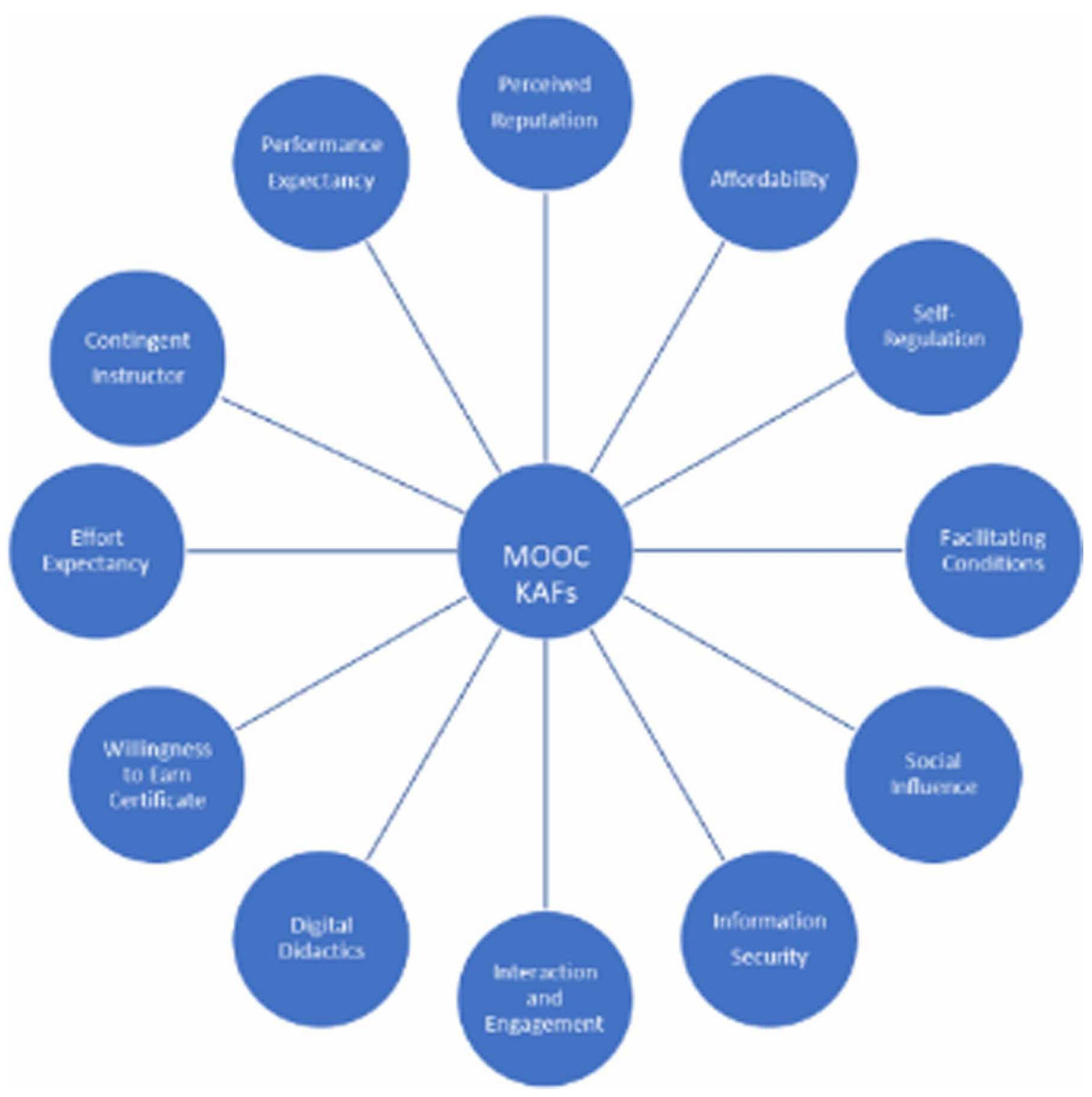

Here, $a_{i j}=\left(x_{i j}, y_{i j}, z_{i j}\right)$ is a TFN derived from linguistic term given by the $i$ th expert (DM), to the $j$ th KAF. $i=1,2,3, ., m$ are the numbers of expert and $j=1,2,3 \ldots ., n$ are the numbers of KAFs.

Step 3 Normalization of fuzzy decision matrix A produces fuzzy unweighted matrix R. To produce R, equation (3) can be applied. The study considered only benefit criteria to determines acceptance (Lai et al.,2010).

$$
R=\left[r_{i j}\right]_{m x n} \quad r i_{j}=\left(\frac{x_{i j}}{z_{i j}^{*}} \frac{y_{i j}}{z_{i j}^{*}} \frac{z_{i j}}{z_{i j}^{*}}\right)
$$


Figure 3. Linguistics scales and triangular fuzzy numbers

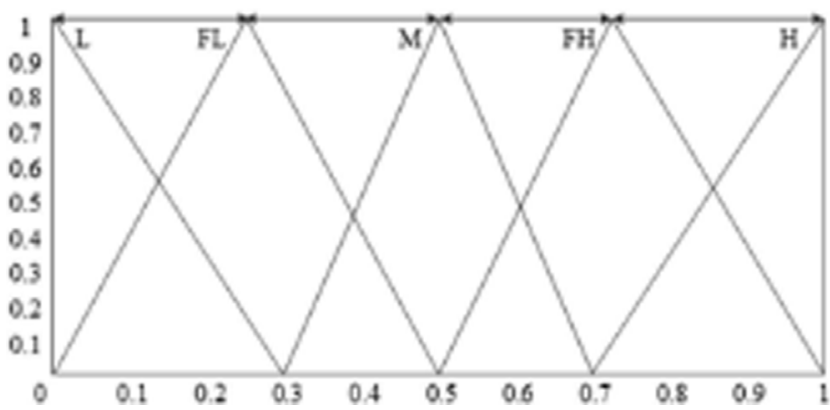

Table 3. Transformation Rules

\begin{tabular}{|c|c|}
\hline Linguistic term & Triangular fuzzy number \\
\hline Low (L) & $(0.0,0.1,0.3)$ \\
\hline Fairly Low (FL) & $(0.1,0.3,0.5)$ \\
\hline Medium (M) & $(0.3,0.5,0.7)$ \\
\hline Fairly High (FH) & $(0.5,0.7,0.9)$ \\
\hline High (H) & $(0.7,0.9,1.0)$ \\
\hline
\end{tabular}

where $C_{j=}^{*} \max _{i} C \mathrm{i}=1,2,3, \ldots \ldots, \mathrm{m} ; \mathrm{j}=1,2,3, \ldots, \mathrm{n}$ (Benefit Criteria)(Agrawal et al., 2015)

Step 4 Compute values for the weighted normalized decision matrix (V) to construct it.

$\mathrm{V}=\left[v_{i j}\right]_{m x n} ; \mathrm{i}=1,2,3, \ldots, \mathrm{m}$ and $\mathrm{j}=1,2,3, \ldots, \mathrm{n}$

Each weighted normalized value $v_{\mathrm{ij}}$ is calculated by multiplying each element with its associated weight as shown in equation (5).

$v_{i j}=r_{i j} \times w_{j}$

The current work assigns same weight to every expert $\mathrm{w}_{\mathrm{j}}=(1,1,1,1,1) \forall_{j} \in n$ (Agrawal et al., 2015).

Step 5 Calculate the ideal $\left(P^{*}\right)$ and negative-ideal $\left(P^{-}\right)$solution for the KAFs as defined in equation (6) and (7).

$P^{*}=\left\{v_{1}^{*}, v_{2}^{*}, v_{3}^{*}, \ldots \ldots \ldots, v_{n}^{*}\right\}$ 


$$
P^{-}=\left\{v_{1}^{-}, v_{2}^{-}, v_{3}^{-}, \ldots \ldots \ldots, v_{n}^{-}\right\}
$$

The terms shown in equation (8) and (9) are utilized for positive and negative ideal solutions.

$$
\begin{aligned}
& v_{j}^{*}=(1,1,1) \\
& v_{j}^{-}=(0,0,0)
\end{aligned}
$$

Step 6 Computation of the sum of distances from positive and negative ideal solution is done for every KAF using the equation 10 .

$$
D_{j}^{*}=\frac{\sum_{i=1}^{m} d\left(v_{i j}=v_{i}^{*}\right)}{m}, \mathbf{j}=1,2,3, . ., \mathrm{n}
$$

where $d\left(v_{i j}-v_{i}^{*}\right)$ is the distance between two fuzzy numbers. It is calculated using vector algebra. For example, To calculate the distance between two numbers $A 1\left(a_{1}, b_{1}, c_{1}\right)$ and $A 2\left(a_{2}, b_{2}, c_{2}\right)$ in vector algebra following formula can be used, show in equation 11.

$$
\mathrm{d}(\mathrm{A} 1-\mathrm{A} 2)=\sqrt{\frac{1}{3}\left[\left(a_{1}-a_{2}\right)^{2}+\left(b_{1}-b_{2}\right)^{2}+\left(c_{1}-c_{2}\right)^{2}\right]}
$$

Similarly using equation 12 , the distance from the fuzzy negative ideal solution is calculated.

$$
D_{j}^{-}=\frac{\sum_{i=1}^{m} d\left(v i_{j}-v_{i}^{-}\right)}{m}, \mathrm{j}=1,2,3, \ldots \ldots, \mathrm{n}
$$

Step 7 Calculate the relative closeness coefficient to the ideal solution of every KAF. The relative closeness coefficient with respect to $\mathrm{P}^{*}$ is calculated as specified in equation (13).

$$
c j=\frac{d_{j}^{-}}{d_{j}^{*}+d_{j}^{-}}
$$

Step 8 Finally, values of $c_{j}$ for every KAFs are sorted in descending order. 


\section{Fuzzy AHP (FAHP)}

FAHP solves complex decision problems based on subjective preference given by expert(s) to factors (Saaty, 1980). It utilises fuzzy arithmetic with TFNs and geometric mean approach for normalisation of criteria weight (Chen \& Chen, 2010). Various studies implemented it for calculating weights (Kilic \& Cevikcan, 2011). The current study utilised the Buckley (1985) approach to calculate the normalised weight of the KAFs for classification.

\section{FAHP Algorithm}

Step1: Construct a pair-wise comparison matrix showing the preference of one KAF over other KAF. For giving preference, table 4 containing linguistic scale along with TFNs values can be used.

Step2: Now geometric mean method is applied for calculating synthetic pair-wise comparison matrix. Geometric mean $Q_{i}$ is defined with the help of formula:

$$
Q_{i}=\left(a_{i j}^{1} \times a_{i j}^{2} \times a_{i j}^{3} \times \ldots \ldots \times a_{i j}^{12}\right)^{1 / 12}
$$

Step3: To compute the weight of every KAF normalisation of synthetic pair-wise comparison matrix. The formula follows here.

$$
W_{i}=Q_{i} \times\left(Q_{1}+Q_{2}+Q_{3}+\cdots Q_{n}\right)^{-1}
$$

Step4: Now, de-fuzzified $\mathrm{W}_{\mathrm{i}}$ (Fuzzy number) using centre of area method proposed by Chou and Chang (2008) and given in equation (3)

$m_{i}=\frac{l w_{i}+m w_{i}+u w_{i}}{3}$

where $\mathrm{l}=$ lower bound, $\mathrm{m}=$ middle bound and $\mathrm{u}=$ upper bound values of weight $W_{i}$.

Step5: Finally, normalised the de-fuzzified number $M_{i}$ using equation (4)

Table 4. Rules for conversions of linguistic scale to TFNs

\begin{tabular}{|l|c|c|}
\hline \multicolumn{1}{|c|}{ Linguistic scale for importance } & Triangular fuzzy scale & Triangular fuzzy reciprocal scale \\
\hline Equally Important (EI) & $(1 / 2,1,3 / 2)$ & $(2 / 3,1,2)$ \\
\hline Weakly More Important (WMI) & $(1,3 / 2,2)$ & $(1 / 2,2 / 3,1)$ \\
\hline Strongly More Important (SMI) & $(3 / 2,2.5 / 2)$ & $(2 / 5,1 / 2,2 / 3)$ \\
\hline Very Strongly More Important (VSMI) & $(2,5 / 2,3)$ & $(1 / 3,2 / 5,1 / 2)$ \\
\hline Absolutely More Important (AMI) & $(5 / 2,3,7 / 2)$ & $(2 / 7,1 / 3,2 / 5)$ \\
\hline
\end{tabular}


$N_{i}=\frac{M_{i}}{\sum_{i=1}^{n} M_{i}}$

\section{KAFs Prioritization Using FTOPSIS}

FTOPSIS algorithm has been applied for MOOC KAFs ranking. To prioritize, a panel of five Indian experts were consulted. The panel had three learned academicians with an average experience of 13 years in the area of consumer behaviour, one MOOC designer having more than 5 years of experience, and a MOOC learner who had completed 12 MOOC courses. Expert's personal and professional details are not mentioned to maintain the confidentiality of data. For reference, experts were coded as DM1 (first expert), DM2 (second expert), DM3 (third expert), DM4(fourth expert), and DM5 (fifth expert). As mentioned in step 1, experts rate all the factors. Table 5 present linguistic assessment given by experts.

As discussed in step 2, linguistic assessments were converted into TFNs using table 3 to generate fuzzy decision matrix A. Step 3 of the algorithm uses equation 3, to produce normalised unweighted fuzzy decision matrix R. Further, equation 5 is applied on unweighted fuzzy decision matrix to produce fuzzy normalized decision matrix V. Following step 5, normalised decision matrix Vis being used to compute the $\left(P^{*}\right)$ and negative-ideal $P^{-}$solution for the KAFs. The step uses equation 6,7,8, and 9 for it. Now, the distance $D_{j}^{*}$ and $D_{j}^{-}$of every KAFs was computed using equations (10) and (12). As mentioned in step 7 of the algorithm, closeness coefficient $C_{j}$ is calculated using equation (13) for every KAFs. Table 6 presents the values of $D_{j}^{*}, D_{j}^{-}$and closeness coefficient $C_{j}$ of every KAFs along with ranking. Closeness coefficient were rank in descending order to obtain the final ranks of KAFs.

\section{KAFs Classification Using FAHP}

For classification, FAHP technique is used. One Indian expert from academia with more than 14 years of experience of teaching MCDM techniques was consulted. Expert also possesses knowledge

Table 5. Decision Matrix using linguistic variables

\begin{tabular}{|l|l|c|c|c|c|c|}
\hline S.no & \multicolumn{1}{|c|}{ KAFs for MOOC acceptance } & DM1 & DM2 & DM3 & DM4 & DM5 \\
\hline 1 & Contingent Instructor (KAF1) & FH & FH & H & H & M \\
\hline 2 & Affordability (KAF2) & H & H & H & FH & FH \\
\hline 3 & Digital Didactics (KAF3) & FH & H & FH & FH & FH \\
\hline 4 & Performance Expectancy (KAF4) & H & FH & FH & H & H \\
\hline 5 & Self-Regulation (KAF5) & FH & FH & FH & M & M \\
\hline 6 & Information Security (KAF6) & FL & M & M & L & L \\
\hline 7 & Facilitating Conditions (KAF7) & M & L & L & M & M \\
\hline 8 & Social Influence (KAF8) & M & M & FH & FH & L \\
\hline 9 & Willingness to earn certificate (KAF9) & FH & FH & M & FL & FH \\
\hline 10 & Perceived Reputation (KAF10) & M & M & M & FH & H \\
\hline 11 & Effort Expectancy (KAF11) & FH & FH & M & M & H \\
\hline 12 & Interaction and Engagement (KAF12) & FH & H & FL & FL & FH \\
\hline
\end{tabular}

L Low, FL Fairly Low, M Medium, FH Fairly High, H High 
Table 6. Closeness coefficient matrix and priority

\begin{tabular}{|l|l|l|l|l|l|l|}
\hline S.no & \multicolumn{1}{|c|}{$\begin{array}{c}\text { KAFs for MOOC } \\
\text { Acceptance }\end{array}$} & $\begin{array}{c}\text { KAFs } \\
\text { Code }\end{array}$ & \multicolumn{1}{|c|}{$D_{j}^{*}$} & \multicolumn{1}{|c|}{$D_{j}^{-}$} & \multicolumn{1}{|c|}{$C_{j}$} & Ranking \\
\hline 1 & Contingent Instructor & KAF1 & 0.31485391 & 0.742954355 & 0.702352571 & 4 \\
\hline 2 & Affordability & KAF2 & 0.246170522 & 0.812875137 & 0.767554383 & 1 \\
\hline 3 & Digital Didactics & KAF3 & 0.309766858 & 0.750155238 & 0.707745636 & 3 \\
\hline 4 & Performance Expectancy & KAF4 & 0.302839281 & 0.812875137 & 0.728569179 & 2 \\
\hline 5 & Self-Regulation & KAF5 & 0.415335466 & 0.641673624 & 0.607065379 & 6 \\
\hline 6 & Information Security & KAF6 & 0.704393523 & 0.351739131 & 0.333044461 & 12 \\
\hline 7 & Facilitating Conditions & KAF7 & 0.665832691 & 0.388624351 & 0.368553991 & 11 \\
\hline 8 & Social Influence & KAF8 & 0.522141469 & 0.534429404 & 0.505815008 & 10 \\
\hline 9 & Willingness to earn certificate & KAF9 & 0.453896299 & 0.604788404 & 0.571263949 & 8 \\
\hline 10 & Perceived Reputation & KAF10 & 0.420422519 & 0.634472742 & 0.601455676 & 7 \\
\hline 11 & Effort Expectancy & KAF11 & 0.383537299 & 0.673033574 & 0.63700 & 5 \\
\hline 12 & Interaction and Engagement & KAF12 & 0.460658963 & 0.599263133 & 0.565384131 & 9 \\
\hline
\end{tabular}

about e-learning tools. As mentioned in the step1 of FAHP algorithm pair-wise decision matrix was created based on the expert input using table 4 . For reference purpose TFN values of only one $\mathrm{KAF}(\mathrm{KAF} 1)$ is shown in table 7.

Step 2 calculates geometric mean using equation (1). For example, $\left((1,1,1) \times\left(\frac{1}{2}, 1, \frac{3}{s}\right) \times \ldots \ldots \times\left(\frac{3}{2}, 2, \frac{5}{2}\right)\right)^{1 / 12}=(1.10,1.51,1.89)$. Step 3 uses equation (2) to computes weight. For instance, weight $W_{1}=(1.10,1.51,1.89) \times(0.82,1.08,1.39)^{-1}=(0.91,1.63,2.65)$. Likewise, weights of the remaining KAFs can be calculated. Table 8shows computed weights of all KAFs. Now step 4 is applied on the computed weight to defuzzify them using equation 3.

Defuzzified weights were further normalised using equation 4 for classification purpose. To classify them based on a criterion, researchers discussed with the same expert. After discussion a criterion for classification is finalised and it is as follows. If normalised weight is greater than or equals to 0.1 then KAF will be grouped under "High Influential" Category. If it is greater than equals to 0.06 but less than 0.1 then it will be considered under "Moderate Influential". Else it will fall under "Low Influential" category.

After successful implementation of FTOPSIS and FAHP on MOOC KAFs results of ranking and classification are shown table 9 and table 10 respectively.

Table 7. KAF values given by expert

\begin{tabular}{|l|c|c|c|c|c|c|c|c|c|}
\hline & KAF1 & KAF2 & KAF3 & ---- & ---- & ----- & ---- & ----- & KAF12 \\
\hline KAF1 & $1,1,1$ & $1 / 2,1,3 / 2$ & $1,3 / 2,2$ & & & & & & $3 / 2,2,5 / 2$ \\
\hline
\end{tabular}


Table 8. KAFs with Computed Weights

\begin{tabular}{|l|l|l|l|l|}
\hline \multicolumn{1}{|c|}{ Factor } & \multicolumn{1}{c|}{ Weight } & \multicolumn{3}{c|}{ Computed Weights } \\
\hline KAF1 & W1 & 0.91 & 1.63 & 2.65 \\
\hline KAF2 & W2 & 1.00 & 1.82 & 3.07 \\
\hline KAF3 & W3 & 0.71 & 1.28 & 2.15 \\
\hline KAF4 & W4 & 1.07 & 1.90 & 3.16 \\
\hline KAF5 & W5 & 0.76 & 1.29 & 2.13 \\
\hline KAF6 & W6 & 0.74 & 1.19 & 1.88 \\
\hline KAF7 & W7 & 0.69 & 1.13 & 1.85 \\
\hline KAF8 & W8 & 0.52 & 0.81 & 1.27 \\
\hline KAF9 & W9 & 0.51 & 0.83 & 1.37 \\
\hline KAF10 & W10 & 0.65 & 1.14 & 2.30 \\
\hline KAF11 & W11 & 0.36 & 0.56 & 0.90 \\
\hline KAF12 & W12 & 0.31 & 0.48 & 0.78 \\
\hline
\end{tabular}

\section{FINDINGS AND DISCUSSION}

Affordability, performance expectancy, and digital didactics have emerged as the top three KAFs. Our finding is in-line with Rao (2006). He found affordability to be a prime indicator in shaping learner's perceptions. Tiwari (2017) reported that India is a pioneer in providing innovations to mix affordability with excellence. SWAYAM is one such effort initiated by the Indian Government in the direction of inclusive education. It provides courses prepared by the best teachers free of cost to learners but examination and certification carries a nominal cost. It fits with the country's current economic scenario at the time of the pandemic. In the developing nation like India, affordability gives a fertile environment of acceptance. The other two criteria, performance expectancy and digital didactics also plays vital role in MOOC acceptance in India. MOOCs would be of great help to Indians because it enabled them to achieve learning outcomes such as skills sharpening and better performance. Digital didactics empowers online learning by making the learning process simpler and user friendly. Contingent instructor, being a novel factor got the fourth position in the ranking and grouped under the moderate influential category because it offers learning solutions to many learners during pandemic when very limited options of learning are available to them. Information security got the least position in the ranking and also grouped under a low influential category. It is driven by human factors (Alavi et al., 2013). To learn, people need to register themselves by submitting their details at MOOC platforms. It is commonly seen that in India mostly people share their details such as personal and professional information on websites without hesitation. It may be due to lack of awareness regarding information security. This can be a possible reason for getting the lowest rank among KAFs.

\section{CONTRIBUTIONS AND CONCLUSION}

Researchers contacted experts for linguistic assessment. All experts belonged to India. Linguistic assessment given by experts in decision matrix represents the preference of a particular factor to an Indian MOOC learner. Thus, the investigation presents a unique approach to describe MOOC acceptance among Indian learner by ranking and grouping MOOC KAFs. The study gives strong recommendations to MOOC stakeholders based on KAFs in order to boost acceptance of MOOC 
Table 9. KAFs ranking using Fuzzy TOPSIS

\begin{tabular}{|l|l|l|l|}
\hline \multicolumn{1}{|c|}{ S.no } & \multicolumn{1}{c|}{ KAFs for MOOC Acceptance } & \multicolumn{1}{c|}{ KAFs } & \multicolumn{1}{c|}{ Ranking } \\
\hline 1 & Affordability & KAF2 & 1 \\
\hline 2 & Performance Expectancy & KAF4 & 2 \\
\hline 3 & Digital Didactics & KAF3 & 3 \\
\hline 4 & Contingent Instructor & KAF1 & 4 \\
\hline 5 & Effort Expectancy & KAF11 & 5 \\
\hline 6 & Self-Regulation & KAF5 & 6 \\
\hline 7 & Perceived Reputation & KAF10 & 7 \\
\hline 8 & Willingness to earn certificate & KAF9 & 8 \\
\hline 9 & Interaction and Engagement & KAF12 & 9 \\
\hline 10 & Social Influence & KAF8 & 10 \\
\hline 11 & Facilitating Conditions & KAF7 & 11 \\
\hline 12 & Information Security & KAF6 & 12 \\
\hline
\end{tabular}

Table 10. KAFs classification using Fuzzy AHP

\begin{tabular}{|c|c|c|c|c|}
\hline S.no & KAFs for MOOC Acceptance & KAFs & $\begin{array}{l}\text { Normalised } \\
\text { Weight }\left(N_{i}\right)\end{array}$ & Group \\
\hline 1 & Affordability & KAF2 & 0.16 & \multirow{3}{*}{$\begin{array}{l}\text { Highly Influential } \\
\text { (Group-1) }\end{array}$} \\
\hline 2 & Performance Expectancy & KAF4 & 0.14 & \\
\hline 3 & Digital Didactics & KAF3 & 0.12 & \\
\hline 4 & Contingent Instructor & KAF1 & 0.09 & \multirow{5}{*}{$\begin{array}{l}\text { Moderate Influential } \\
\text { (Group-2) }\end{array}$} \\
\hline 5 & Effort Expectancy & KAF11 & 0.08 & \\
\hline 6 & Self-Regulation & KAF5 & 0.07 & \\
\hline 7 & Perceived Reputation & KAF10 & 0.06 & \\
\hline 8 & Willingness to earn certificate & KAF9 & 0.06 & \\
\hline 9 & Interaction and Engagement & KAF12 & 0.05 & \multirow{4}{*}{$\begin{array}{l}\text { Low Influential } \\
\text { (Group-3) }\end{array}$} \\
\hline 10 & Social Influence & KAF8 & 0.05 & \\
\hline 11 & Facilitating Conditions & KAF7 & 0.04 & \\
\hline 12 & Information Security & KAF6 & 0.04 & \\
\hline
\end{tabular}

among learners. The top three factors in the ranking are affordability, performance expectancy, and digital didactics. They are also part of the most influential factors of MOOC acceptance. Affordability was a prime factor of MOOC acceptance for Indian learners. Some MOOC platform charges fee for their courses. Fee charged for a course sometimes does not fit in the budget of a learner. The reason is many Indians falls in the lower and middle-income strata and affordable learning matters to them. Sometimes these learners leave their studies due to economic challenges in their lives. Due to economic 
challenges, they cannot spend money on courses for learning. If MOOC stakeholders really want to increase the acceptability of MOOC in developing nations, they need to take up call on affordability. They must give motivational provision (e.g. monetary and non-monetary benefits) to learners for completing their course and earn certificate for free. It can be done using provision of giving badges to learners during the course. If a learner consistently performs in the assignments given by instructor, then learner would get a digital badge for it. Based on the digital badges earned in a course learner would be given an opportunity to appear in the examination and take certificate of the course absolutely free. It would motivate learners who are deprived due to economic barriers. This motivational provision would generate higher enrolment numbers, help in controlling attrition. It would further support in achieving the objectives of inclusive education. As projected by Morgan Stanley, India's internet users will increase to 914 million from 670 million by 2027. There is tremendous scope of MOOC acceptance. Thus, the MOOC provider must give due attention to affordability aspect. PE holds the second position in the ranking. Venkatesh and Davis (2000) observed PE as a strong determinant of acceptance in voluntary settings. MOOC learning is also voluntary self-regulated learning (Park et al.,2015). For wider acceptance of MOOC, MOOC developers need to design courses which can offer learners professional and career benefits. To match the learning intentions with actual learning experience MOOC developers, need to update their curriculum as per changing needs of industry. In this way they can increase its usefulness for learners. This finding is supported by the corroboration of recent studies which considered it to be a significant factor of adoption in educational settings (Mulik et al., 2018; Fianu et al., 2018; Sharma et al., 2017). Since, performance expectancy is found to be key factor of MOOC acceptance among Indian learners. MOOC providers and developers should concentrate on the themes that are demanded by industry. In this manner, MOOC can support learner by two ways. First, it will make the unemployed learner job ready. Second, it will support the industry professional in their career advancement. Digital didactics has been ranked among the top 3 factors. Digital didactics gives positive results in terms of comprehension and enhances learner's motivation in autonomous learning (Chuquín et al.,2020). It gives learners an opportunity to enhance individual as well as group knowledge by active engagement. Rodríguez-Ardura and Meseguer-Artola (2016) suggested that it gives extraordinary interactivity support in learning and increases learners' willingness to continue with MOOCs. To have widespread acceptance, providers must give digital material in a very simple form so that novice learners can easily utilize it for learning purposes. There is tremendous scope of improvement in the current practices of MOOCs. These aforementioned recommendations give a significant ramification to building and promoting viable MOOC learning frameworks in developing nations.

The study identified eleven KAFs from academic literature and proposed one new KAF taking into account the perspective of Indian learners. These 12 KAFs are a comprehensive package of learner's characteristics, course attributes, as well as societal and technical attributes. It would help developers in designing effective MOOCs. KAFs are ranked and classified using two popular FMCDM techniques, FTOPSIS and FAHP respectively. Authors noticed that MOOC acted as a contingent instructor giving support to learners in completing their studies during pandemic. The procedure adopted in the investigation is a proper mix of literature review, group decision making, and mathematical techniques. Thus, the procedure is reasonably effective, pragmatic, and robust. The findings will help MOOC providers to redesign strategies of MOOC acceptance for developing nations like India.

\section{Limitations and Future Directions}

The MOOC scenario in developing nations considering technological infrastructure, literacy level, digital divide, political and social scenario is not the same as that of developed nations. There may be differences in the findings of this exploration with research that concentrated solely on developed nations. So, similar research may be conducted in developed nations to compare the findings with this study. KAFs were ranked and classified on the opinion of a limited number of experts. Future 
studies may include the opinion of a larger number of experts. The authors proposed a "contingency instructor" as a novel factor considering the current Covid-19 pandemic and forthcoming new normal situation. Further, research may be conducted to verify the importance of this factor. Other multicriteria decision-making techniques such as Multi moora, Electre may be used in future research and results obtained using those methods may be compared with these research results. 


\section{REFERENCES}

Abdeen, H., Zaben, M., \& Staya, A. (2008). The Value of E-Learning in the Palestinian Medical School. 1st E-Learning Excellence Forum, Dubai, UAE.

Adams, A., \& Blandford, A. (2003). Security and online learning: To protect or prohibit. Usability Evaluation of Online Learning Programs, 331-359.

Agrawal, S., Singh, R. K., \& Murtaza, Q. (2016). Prioritizing critical success factors for reverse logistics implementation using fuzzy-TOPSIS methodology. J Ind Eng Int, 12(1), 15-27. doi:10.1007/s40092-015-0124-8

Alavi, R., Islam, S., Jahankhani, H., \& Al-Nemrat, A. (2013). Analyzing human factors for an effective information security management system. International Journal of Secure Software Engineering, 4(1), 50-74. doi:10.4018/ jsse.2013010104

Alghamdi, T., Zedan, H., \& Alzahrani, A. (2011). Enforcing Learning Activities Policies in Runtime Monitoring System for E-learning Environments. Journal of Computer Science and Information Security, 9(8), 45-53.

Alraimi, K. M., Zo, H., \& Ciganek, A. P. (2015). Understanding the MOOCs continuance: The role of openness and reputation. Computers \& Education, 80, 28-38. doi:10.1016/j.compedu.2014.08.006

Banaitiene, N., Banaitis, A., Kaklauskas, A., \& Zavadskas, E. K. (2008). Evaluating the life cycle of a building: A multivariant and multiple criteria approach. Omega, 36(3), 429-441. doi:10.1016/j.omega.2005.10.010

Buckley, J. J. (1985). Fuzzy hierarchical analysis. Fuzzy Sets and Systems, 17(1), 233-247. doi:10.1016/01650114(85)90090-9

Chang, C. T., Tan, K. H., \& Lu, H. C. (2014). Multiple criteria decision making theory, methods, and applications in engineering. Mathematical Problems in Engineering, 2014.

Chellapalli, T., \& Kumar, D. V. S. (2016). Electronic Payment Systems: Role of Demographics. SCMS Journal of Indian Management, 13(4).

Chen, C. T. (2001). A fuzzy approach to select location of the distribution center. Fuzzy Sets and Systems, 118(1), 65-73. doi:10.1016/S0165-0114(98)00459-X

Chen, J. K., \& Chen, I. S. (2010). Using a novel conjunctive MCDM approach based on DEMATEL, fuzzy ANP, and TOPSIS as an innovation support system for Taiwanese higher education. Expert Systems with Applications, 37(3), 1981-1990. doi:10.1016/j.eswa.2009.06.079

Chou, S. W., \& Chang, Y. C. (2008). The implementation factors that influence the ERP (Enterprise Resource Planning) Benefits. Decision Support Systems, 46(1), 149-157. doi:10.1016/j.dss.2008.06.003

Chuquín, M., Paguay, J., \& Mora, S. (2020). Impact of the Digital Didactic Material on Students' Reading and Grammar Acquisition. Universitas Tarraconensis. Revista de Ciències de l'Educació., 1(1), 22. doi:10.17345/ ute.2020.1.2624

Cohen, J. (1960). A coefficient of agreement for nominal scales. Educational and Psychological Measurement, 20(1), 37-46. doi:10.1177/001316446002000104

Dhawal, S. (2020). By the Numbers: MOOCs During the Pandemic. https://www.classcentral.com/report/moocstats-pandemic/

Ebben, M., \& Murphy, J. S. (2014). Unpacking MOOC scholarly discourse: A review of nascent MOOC scholarship. Learning, Media and Technology, 39(3), 328-345. doi:10.1080/17439884.2013.878352

Fianu, E., Blewett, C., Ampong, G., \& Ofori, K. (2018). Factors Affecting MOOC Usage by Students in Selected Ghanaian Universities. Education Sciences, 8(2), 70. doi:10.3390/educsci8020070

Gefen, D., Karahanna, E., \& Straub, D. W. (2003). Trust and TAM in Online Shopping: An Integrated Model. Management Information Systems Quarterly, 27(1), 51-90. doi:10.2307/30036519

Gewnhi, P., Bavel, J. J. V., Vasey, M. W., \& Thayer, J. F. (2013). Cardiac vagal tone predicts attentional engagement to and disengagement from fearful faces. Emotion (Washington, D.C.), 13(4), 645-656. doi:10.1037/a0032971 PMID:23914769 
Gregori, E. B., Zhang, J., Galván-Fernández, C., \& Fernández-Navarro, F. D. A. (2018). Learner support in MOOCs: Identifying variables linked to completion. Computers \& Education, 122, 153-168. doi:10.1016/j. compedu.2018.03.014

Hew, K. F., \& Cheung, W. S. (2014). Students' and instructors' use of massive open online courses (MOOCs): Motivations and challenges. Educational Research Review, 12, 45-58. doi:10.1016/j.edurev.2014.05.001

Hooda, M., \& Jain, A. (2018). Service Quality Model of Higher Education: On Developing Nation. SCMS Journal of Indian Management, 15, 4.

Hughes-Morley, A., Young, B., Waheed, W., Small, N., \& Bower, P. (2015). Factors affecting recruitment into depression trials: Systematic review, meta-synthesis and conceptual framework. Journal of Affective Disorders, 172, 274-290. doi:10.1016/j.jad.2014.10.005 PMID:25451427

Kansanen, P., \& Meri, M. (1999). The didactic relation in the teaching-studying-learning process. TNTEE Publications.

Kilic, H. S., \& Cevikcan, E. (2011). Job Selection Based on Fuzzy AHP: An investigation including the students of Istanbul Technical University Management Faculty. International Journal of Business and Management Studies, 3(1), 173-182.

Kumar Sharma, S., Jain Palvia, S. C., \& Kumar, K. (2017). Changing the landscape of higher education: From standardized learning to customized learning. Journal of Information Technology Case and Application Research, 19(2), 75-80. doi:10.1080/15228053.2017.1345214

Lai, C. K., Chung, J. C., Leung, N. K., Wong, J. C., \& Mak, D. P. (2010). A survey of older Hong Kong people's perceptions of telecommunication technologies and telecare devices. Journal of Telemedicine and Telecare, 16(8), 441-446. doi:10.1258/jtt.2010.090905 PMID:20870685

Landis, J. R., \& Koch, G. G. (1977). The measurement of observer agreement for categorical data. Biometrics, 33(1), 159-174. doi:10.2307/2529310 PMID:843571

Laurillard, D. (2016). The educational problem that MOOCs could solve: Professional development for teachers of disadvantaged students. Research in Learning Technology, 24(1063519), 1-17. doi:10.3402/rlt.v24.29369

Liberati, A., Altman, D., Tetzlaff, J., Mulrow, C., Gøtzsche, P., Ioannidis, J., Clarke, M., Devereaux, P. J., Kleijnen, J., \& Moher, D. (2009). The PRISMA Statement for Reporting Systematic Reviews and Meta-Analyses of Studies That Evaluate Health Care Interventions: Explanation and Elaboration. Journal of Clinical Epidemiology, 62(10), e1-e34. doi:10.1016/j.jclinepi.2009.06.006 PMID:19631507

Liyanagunawardena, T. R., Adams, A. A., \& Williams, S. A. (2013). MOOCs: a systematic study of the published literature 2008e2012. The International Review of Research in Open and Distance Learning, 14(3), $202-227$.

Ma, L., \& Lee, C. S. (2019). Investigating the adoption of MOOCs: A technology-user-environment perspective. Journal of Computer Assisted Learning, 35(1), 89-98. doi:10.1111/jcal.12314

Macleod, H., Haywood, J., Woodgate, A., \& Alkhatnai, M. (2015). Emerging patterns in MOOCs: Learners, course designs and directions. TechTrends, 59(1), 56-63. doi:10.1007/s11528-014-0821-y

Mohapatra, S., \& Mohanty, R. (2016). Adopting MOOCs for affordable quality education. Education and Information Technologies, 22(5), 2027-2053. doi:10.1007/s10639-016-9526-5

Mohapatra, S., Rohit, P., \& Subrata, M. (2015). Study of motivational factors post-implementing ERP (SAP) solutions in National Aluminium Company Limited extending the technology acceptance model at organisation level (TAMO). International Journal of Management and Enterprise Development, 14(3), 250-271. doi:10.1504/ IJMED.2015.073444

Moher, D., Liberati, A., Tetzlaff, J., \& Altman, D. G. (2009). Preferred reporting items for systematic reviews and meta-analyses: The PRISMA statement. Annals of Internal Medicine, 151(4), 264-269. doi:10.7326/00034819-151-4-200908180-00135 PMID:19622511

Mulik, Srivastava, \& Yajnik. (2018, August). Extending UTAUT Model to Examine MOOC Adoption. NMIMS Management Review, 36(2). 
Nemer, D., \& O’Neill, J. (2019). Rethinking MOOCs: The Promises for Better Education in India. International Journal of Information Communication Technologies and Human Development, 11(1), 36-50. doi:10.4018/ IJICTHD.2019010103

Nguyen-Duc, A., Cruzes, D. S., \& Conradi, R. (2015). The impact of global dispersion on coordination, team performance and software quality-a systematic literature review. Information and Software Technology, 57, 277-294. doi:10.1016/j.infsof.2014.06.002

Onah, D., \& Sinclair, J. (2016). Exploring learners' strategies of self regulated learning abilities in a novel MOOC Platform: eLDa. Paper presented at the 23rd annual conference of the Association for Learning Technology.

Paliwoda-Pękosz, G., \& Stal, J. (2015). ICT in supporting content and language integrated learning: Experience from Poland. Information Technology for Development, 21(3), 403-435. doi:10.1080/02681102.2014.1003521

Park, Y., Jung, I., \& Reeves, T. C. (2015). Learning from MOOCs: A qualitative case study from the learners' perspectives. Educational Media International, 52(2), 72-87. doi:10.1080/09523987.2015.1053286

Paulsen, M. (1993) The Hexagon of Cooperative Freedom: A Distance Education Theory Attuned to Computer Conferencing. DEOS News, 3, 1-9. http://nettskolen.nki.no/forskning/21/hexagon.html

Quadri, N. N. (2020). Evaluating critical success factors in implementing E-learning system using multi-criteria decision-making. PLoS One, 15(5), e0231465. doi:10.1371/journal.pone.0231465 PMID:32365123

Saaty, T. L. (1980). The analytic hierarchy process. McGraw-Hill.

Serb, A., Defta, C., Iacob, N. M., \& Apetrei, M. C. (2013). Information security management in e-learning. Knowledge Horizons, 5(2), 55-59.

Shapiro, H. B., Lee, C. H., Wyman Roth, N. E., Li, K., Çetinkaya-Rundel, M., \& Canelas, D. A. (2017). Understanding the massive open online course (MOOC) student experience: An examination of attitudes, motivations, and barriers. Computers \& Education, 110, 35-50. doi:10.1016/j.compedu.2017.03.003

Sharma, S. K., Sarrab, M., \& Al-Shihi, H. (2017). Development and validation of mobile learning acceptance measure. Interactive Learning Environments, 25(7), 847-858. doi:10.1080/10494820.2016.1224250

Stracke, C. M., Hernández, R., Delgado Kloos, C., Pérez Sanagustin, M., \& Teixeira, A. M. (2018). How to make MOOCs better for specific target groups and developing countries? Academic Press.

Subba Rao, S. (2006). Distance education and the role of IT in India. The Electronic Library, 24(2), $225-236$. doi:10.1108/02640470610660396

Sun, C., \& Lin, G. T. R. (2009). Using fuzzy TOPSIS method for evaluating the competitive advantages of shopping websites. Expert Systems with Applications, 36(9), 11764-11771. doi:10.1016/j.eswa.2009.04.017

Tiwari, R. (2017). Frugality in Indian Context: What Makes India a Lead Market for Affordable Excellence? . 10.1007/978-3-319-46392-6_3

Van Laarhoven, P. J. M., \& Pedrycz, W. (1983). A fuzzy extension of Saaty"s priority Theory. Fuzzy Sets and Systems, 11(1-3), 199-227. doi:10.1016/S0165-0114(83)80082-7

Venkatesh, V., \& Davis, F. D. (2000). A theoretical extension of the technology acceptance model: Four longitudinal field studies. Management Science, 46(2), 186-204. doi:10.1287/mnsc.46.2.186.11926

Venkatesh, V., Morris, M. G., Hall, M., Davis, G. B., \& Davis, F. D. (2003). User acceptance of information technology: Toward a unified view. Management Information Systems Quarterly, 27(3), 425-478. doi:10.2307/30036540

Williams, M. D., Rana, N. P., \& Dwivedi, Y. K. (2015). The unified theory of acceptance and use of technology (UTAUT): a literature review. Journal of Enterprise Information Management, 28(3), 443-488.10.1108/JEIM09-2014-0088

Zhao, H., \& Guo, S. (2014). Selecting green supplier of thermal power equipment by using a hybrid MCDM method for sustainability. Sustainability, 6(1), 217-235. doi:10.3390/su6010217 
Zhenghao, C., Alcorn, B., Christensen, G., Eriksson, N., Koller, D., \& Emanuel, E. (2015). Who's benefiting from MOOCs, and Why. Harvard Business Review, 22.

Zhou, Q., Lee, C. S., \& Sin, J. S.-C. (2017). Using social media in formal learning: Investigating learning strategies and satisfaction. Proceedings of the Association for Information Science and Technology, 54(1), 472-482. doi:10.1002/pra2.2017.14505401051

Neeraj Chopra is a research scholar in the Department of Management Studies at J.C. Bose University of Science and Technology, YMCA, Faridabad. He has presented various papers in National and International Conferences, He has over 19 years of experience in academics.

Rajiv Sindwani holds PhD degree in the area of service quality management. Currently he is working as assistant professor in the Department of Management Studies at J C Bose University of Science and Technology, YMCA, Faridabad, India. He is having total 15 years of experience in various sectors including consumer durables, banking, and education. He has published many papers in reputed international journals and also presented papers in various national and international conferences.

Manisha Goel is PhD in Management. She has authored many papers in National and International journals. She has guided research scholars at postgraduate and doctorate levels. With more than 15 years of teaching and research experience, currently, she is working as Associate Professor in the Department of Management Studies at J C Bose University of Science and Technology, YMCA, Faridabad, India. 